\title{
Effect of Polymer Binder on the Transparent Conducting Electrodes on Stretchable Film Fabricated by Screen Printing of Silver Paste
}

\author{
Chan Kyu Lim, ${ }^{1}$ Yo Seb Lee, ${ }^{2}$ Sung Hoon Choa, ${ }^{2}$ Deuk Young Lee, ${ }^{3}$ \\ Lee Soon Park, ${ }^{4}$ and Su Yong Nam ${ }^{1}$ \\ ${ }^{1}$ Department of Graphic Arts Information Engineering, Pukyong National University, Busan 48547, Republic of Korea \\ ${ }^{2}$ Graduate School of NID Fusion Technology, Seoul National University of Science and Technology, Seoul 01811, Republic of Korea \\ ${ }^{3}$ ELK Corporation, Daejeon 34013, Republic of Korea \\ ${ }^{4}$ School of Material Science and Engineering, Ulsan National Institute of Science and Technology (UNIST), \\ Ulsan 44919, Republic of Korea \\ Correspondence should be addressed to Su Yong Nam; suynam@pknu.ac.kr
}

Received 3 July 2017; Accepted 17 September 2017; Published 23 October 2017

Academic Editor: Zhe Qiang

Copyright (c) 2017 Chan Kyu Lim et al. This is an open access article distributed under the Creative Commons Attribution License, which permits unrestricted use, distribution, and reproduction in any medium, provided the original work is properly cited.

\begin{abstract}
Smart wearable devices and sensors have been fabricated by screen printing of metal paste as functional circuits since the metal interconnects exhibited much less electrical resistance than other conducting materials such as carbon nanotube or conducting polymers (PEDOT:PSS). In this study, we chose silver particle as conductive material in the form of silver paste and used screen printing to fabricate a stretchable touch screen panel utilizing metal mesh method for the transparent electrode patterning. The rheological study of Ag pastes showed that the binder polymer with high molecular weight and low glass transition temperature $\left(T_{g}\right)$ can stabilize the Ag paste with Ag particle content over $80 \%$ by weight. The stretching and bending tests of Ag electrode films obtained by screen printing indicated that good conductivity of Ag electrodes is related to the stability of Ag paste obtained with the high molecular weight binder polymer.
\end{abstract}

\section{Introduction}

Transparent conducting electrode is widely used in touch screen panels (TSPs), flexible displays, and wearable devices [1-3]. The printed electronics enable a fast and continuous process in a large scale at ambient temperature [4-6]. Screen printing is a low-cost process to fabricate a transparent conducting film for TSPs compared to the photolithographic process which involves metal thin film deposition, UV exposure, and development conducted in the clean room. Various materials including indium-tin oxide (ITO), carbon nanotube (CNT), silver nanoparticle/nanowire, and conducting polymer (PEDOT:PSS) have been used as interconnects for the fabrication of smart displays and wearable devices $[4,5]$. In contrast to the conventional electronics based on rigid circuit boards or flexible films such as polyester or polyimide film, the stretchable electronic devices need to be fabricated on elastomeric polymer films such as polyurethane and polydimethylsiloxane.

As for the conductive materials, the CNT compounds and conducting polymer (PEDOT:PSS) can be stretched to high elongations but suffer from high electrical resistance. However, metal interconnects based on metal nanopowder or metal nanowire show much less electrical resistance although they have limitation in the high elongation $[7,8]$. In this study, we chose silver particle as conductive material in the form of silver paste and used screen printing to fabricate a stretchable touch screen panel utilizing metal mesh method for the transparent electrode patterning.

\section{Materials and Method}

2.1. Materials and Preparation of Silver Paste. The substrates tested include both rigid and stretchable films with high 


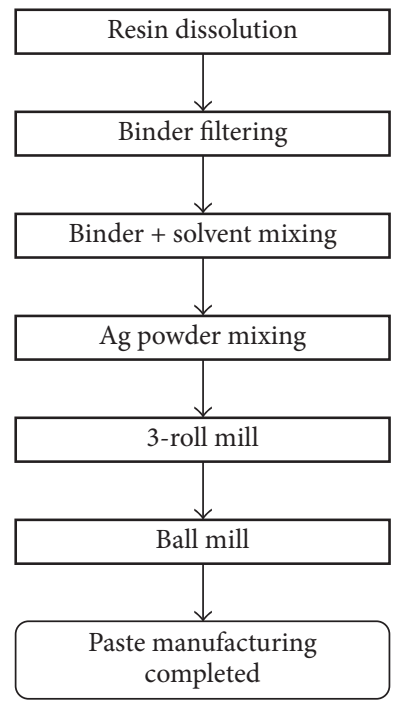

Figure 1: Preparation process of Ag paste.

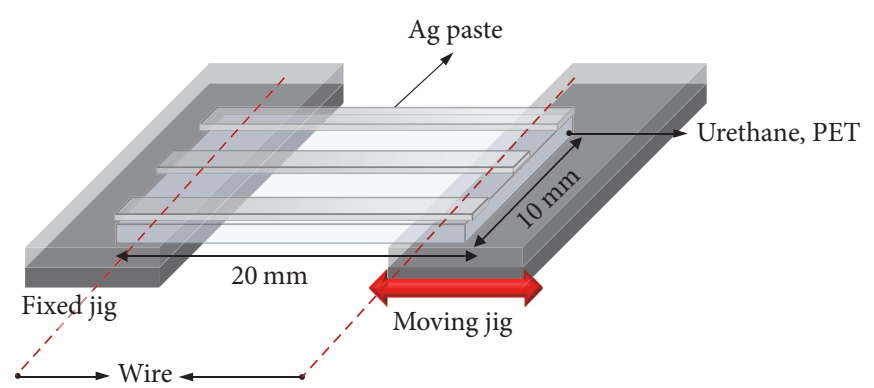

(a)

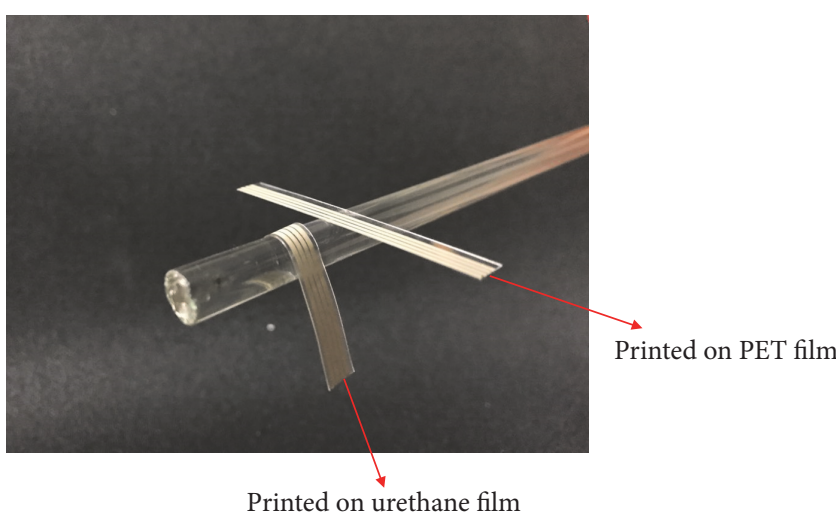

(b)

FIGURE 2: Screen printing of Ag paste: (a) electrode pattern and (b) Ag electrodes on polyester and polyurethane films.

visible light transmittance in the range of $92.2 \%-92.5 \%$ such as polyester and thermoplastic polyurethane films. The unsaturated polyesters with different molecular weight and glass transition temperatures $\left(T_{g}\right)$ were used as binder polymer to make silver paste. The flake type silver powder had average diameter of $1.93 \mu \mathrm{m}$ and top density of $3.52 \mathrm{~g} / \mathrm{cc}$. 2Ethoxyethyl acetate (ECA) and benzoyl peroxide were used as solvent and thermal initiator. 3-Aminopropyltriethoxysilane was used as coupling agent for improved adhesion of the silver paste. The preparation of silver paste is shown in Figure 1. First, the unsaturated polyester resin and ECA solvent were added to three-neck flask at $50: 50 \mathrm{wt} \%$ ratio and stirred at $65^{\circ} \mathrm{C}$ for 24 hour followed by filtration with 300 mesh screen. The concentrated binder polymer solution was diluted with ECA solvent and mixed with silver powder followed by addition of dispersant (BYK-180), coupling agent, and thermal initiator. The resulting Ag pastes were milled 5 times with 3-roll mill (Gyeongyong Machinery Co., Korea) and further stabilized by roll miller at $10 \mathrm{rpm}$ for $24 \mathrm{hr}$ before subjecting to the rheological tests and screen printing.
2.2. Electrode Patterning by Screen Printing and Measurements. Silver electrode patterns (line $/$ space $=1 \mathrm{~mm} / 1 \mathrm{~mm}$ ) were obtained by screen printing method on the stretchable polyurethane (thickness $200 \mu \mathrm{m}$ ) and relatively rigid polyester $(175 \mu \mathrm{m})$ films as shown in Figure 2. Silver paste printed films were cured at $130^{\circ} \mathrm{C}$ for $30 \mathrm{~min}$ in the box heater. The rheological property of the silver paste was measured at $23^{\circ} \mathrm{C}$ by rotating disk rheometer (Thermohaake, Kheowin Pro. 2.92, Germany).

The variations of electrical resistance with stretching and bending modes were measured by using the polyurethane and polyester films, respectively. For the bending test, the bending radius of curvature was calculated by the following equations as shown in Figure 3:

$$
\begin{aligned}
& \text { Bending radius }\left(r_{1}\right)=\frac{L}{2 \pi \sqrt{d L / L-\pi^{2} h s^{2} / 12 L^{2}}}, \\
& \text { Bending radius }\left(r_{2}\right)=\frac{L-d L}{L} .
\end{aligned}
$$



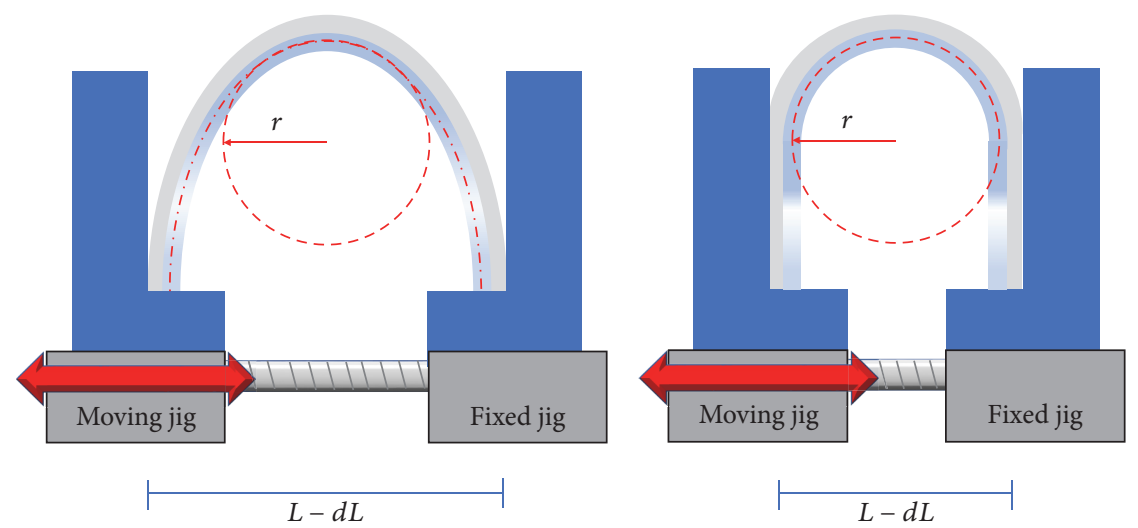

Figure 3: Schematic diagram of bending test.

Here, $L$ is the length of the substrate film, $d L$ is moving distance, and $h s$ is the thickness of the test films. Equation (1) is used in the bending test where the test film is not contacted with the wall of the bending machine, while (2) is used when the film is contacted with the wall.

\section{Results and Discussion}

3.1. Rheological Properties of the Silver Paste. In the screen printing process, the composition of silver paste, especially the binder polymer, plays important role on both the patterning of silver electrodes and the stretching and bending property of the resulting transparent Ag electrode films. In this work, unsaturated polyester resin was used as binder polymer which has good dispersing property of silver particles over $80 \%$ by weight. The unsaturated polyester samples were obtained from SK Chemical Co., Korea, of which molecular weights and glass transition temperatures were measured by GPC and DSC, respectively. Table 1 shows the three different unsaturated polyester resins in terms of molecular weight and glass transition temperature and the formulation of three silver pastes made with the polyester resins.

Here ethoxyethyl acetate (ECA) was used as solvent and the three additives include dispersant (BYK-180, $0.7 \mathrm{wt} \%$ ), silane coupling agent (Shin-Etsu, KBE-903:3, 0.6 wt\%), and thermal initiator (benzoyl peroxide, $0.6 \mathrm{wt} \%$ ). The dispersant BYK-180 was obtained from BKY Co., Germany. It is an acrylate copolymer with carboxylic groups (acid value of $94 \mathrm{mgKOH} / \mathrm{g}$ ) neutralized with alkyl ammonium salt which help dispersion of Ag particles in the ECA solvent.

The viscosity versus shear rate plot of the $\mathrm{Ag}$ pastes obtained at room temperature $\left(23^{\circ} \mathrm{C}\right)$ is shown in Figure 4. The viscosity of the Ag paste was measured first with increasing shear rate and then with decreasing shear rate to get hysteresis loops. The hysteresis loop obtained by the plot of $\mathrm{Ag}$ paste viscosity versus shear rate is closely related to the stability of the well-dispersed Ag paste; the smaller the hysteresis loop the more stable the paste. Although Ag paste (1) and paste (2) had similar hysteresis loop, Ag paste (1) with higher molecular weight (MW) binder polymer than the other two exhibited well-dispersed Ag particles as shown in the optical microscope image (Figure 5) of screen printed

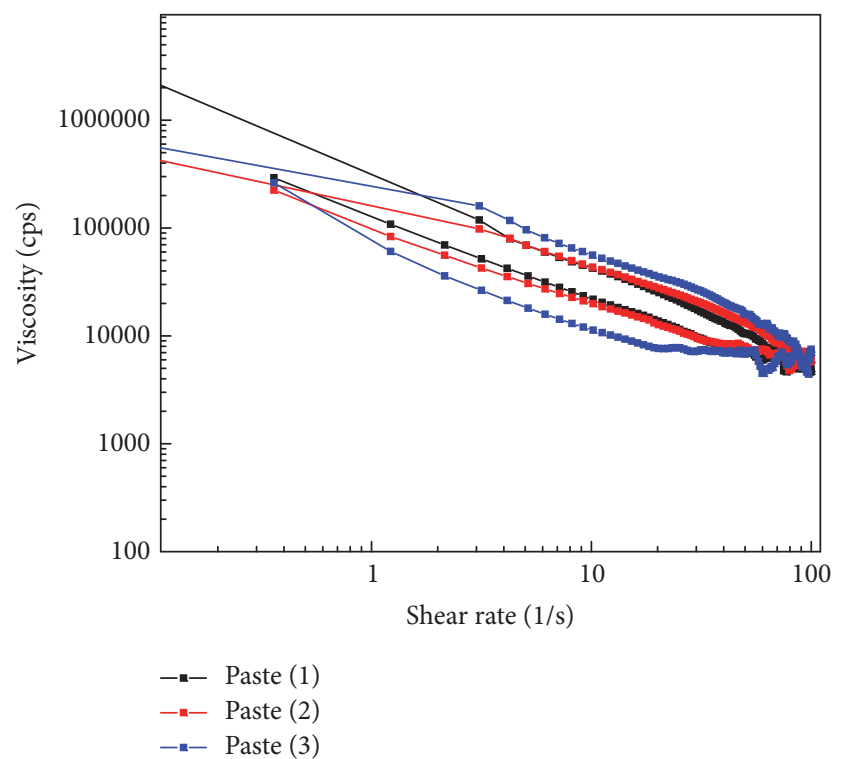

FIGURE 4: Viscosities versus shear rate plot of Ag paste.

electrode. This suggests that the binder polymer with higher MW can stabilize the Ag paste better than the ones with lower MW under the condition of excessive Ag particles (over $80 \%$ by weight) in the paste, which is a requirement setup for the good conductivity of the silver electrodes under high deformation through the percolation mechanism of electrical conduction with silver particles.

The thixotropic index $(\mathrm{TI})$ values defined as TI $=$ (viscosity of paste at $\left.5 \mathrm{~s}^{-1}\right) /\left(\right.$ viscosity of paste at $\left.50 \mathrm{~s}^{-1}\right)$ also support the viscosity versus shear rate plot as shown in Table 2 in which Ag paste (1) made with high MW binder polymer had higher TI values than the other two Ag paste samples.

The storage $\left(G^{\prime}\right)$ and loss $\left(G^{\prime \prime}\right)$ modulus of silver pastes are shown in Figure 6. Ag paste (1) with high MW binder polymer maintained higher storage modulus up to high shear stress than the other two Ag pastes. The high storage modulus of the Ag paste results in increased sharpness of Ag electrodes in the screen printing, which can be maintained after heat curing. This is an important point in the electrical 
TABLE 1: Physical property of binder polymers and formulation of silver pastes.

(a)

\begin{tabular}{lccc}
\hline Binder polymers & Glass transition temp. $\left(T_{g}\right)$ & Mole weight $\left(M_{n}, \mathrm{~g} / \mathrm{mol}\right)$ & Softening temp $\left({ }^{\circ} \mathrm{C}\right)$ \\
\hline Polyester $(1)$ & $16^{\circ} \mathrm{C}$ & 40,000 & $120^{\circ} \mathrm{C}$ \\
Polyester (2) & $70^{\circ} \mathrm{C}$ & 28,000 & $145^{\circ} \mathrm{C}$ \\
Polyester (3) & $10^{\circ} \mathrm{C}$ & 26,000 & $90^{\circ} \mathrm{C}$ \\
\hline
\end{tabular}

(b)

\begin{tabular}{|c|c|c|c|c|c|c|}
\hline Ag pastes (wt\%) & Ag powder & Polyester (1) & Polyester (2) & Polyester (3) & Solvent & Additives \\
\hline Ag paste (1) & 83.4 & 4.1 & & & 10.6 & 1.9 \\
\hline Ag paste (2) & 83.4 & & 4.1 & & 10.6 & 1.9 \\
\hline Ag paste (3) & 83.4 & & & 4.1 & 10.6 & 1.9 \\
\hline
\end{tabular}

TABLE 2: Viscosity and thixotropic index (TI) values of silver pastes.

\begin{tabular}{lcc}
\hline Ag paste & Viscosity $\left(50 \mathrm{~s}^{-1}, \mathrm{cps}\right)$ & $\mathrm{TI}\left(5 / 50 \mathrm{~s}^{-1}\right)$ \\
\hline Ag paste $(1)$ & 10,495 & 6.67 \\
Ag paste $(2)$ & 13,323 & 5.16 \\
Ag paste $(3)$ & 16,128 & 5.81 \\
\hline
\end{tabular}

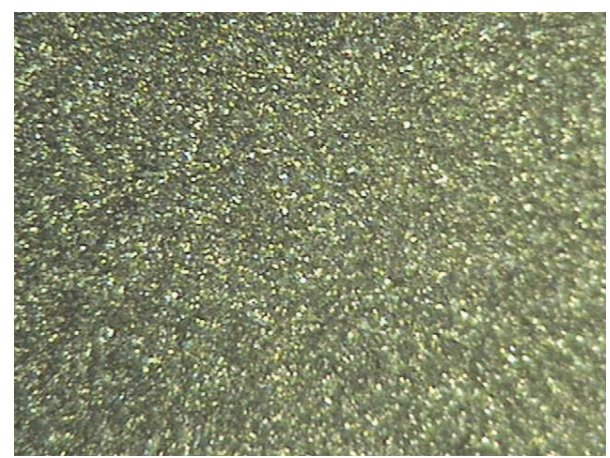

FIGURE 5: Optical microscope image of screen printed Ag electrode $(\times 600)$ by using Ag paste (1).

conductivity of the Ag electrodes under stretching or bending deformations, since the uniform shape of multiple layered Ag particles obtained as a result of increased sharpness during screen printing can meet the requirement of electrical conduction by percolation mechanism. Ag paste (2) showed higher storage modulus than Ag paste (3) while the MW of binder polymers were nearly same. This could be explained by much higher $T_{g}$ value of binder polymer (2) than binder polymer (3), corresponding to more extended polymer conformation or effective molecular weight, thus resulting in higher storage modulus.

3.2. Stretching Test of Silver Electrodes Films. Flexible polyurethane films with patterned silver electrodes and without pattern (Ag paste printed all surface) were subjected to the electrical resistance versus elongation tests as shown in Figures 7 and 8, respectively. The higher the molecular weight of binder polymer in Ag pastes was, the lower the electrical resistance was observed in both the patterned and unpatterned Ag electrode films. It was noted that Ag electrode

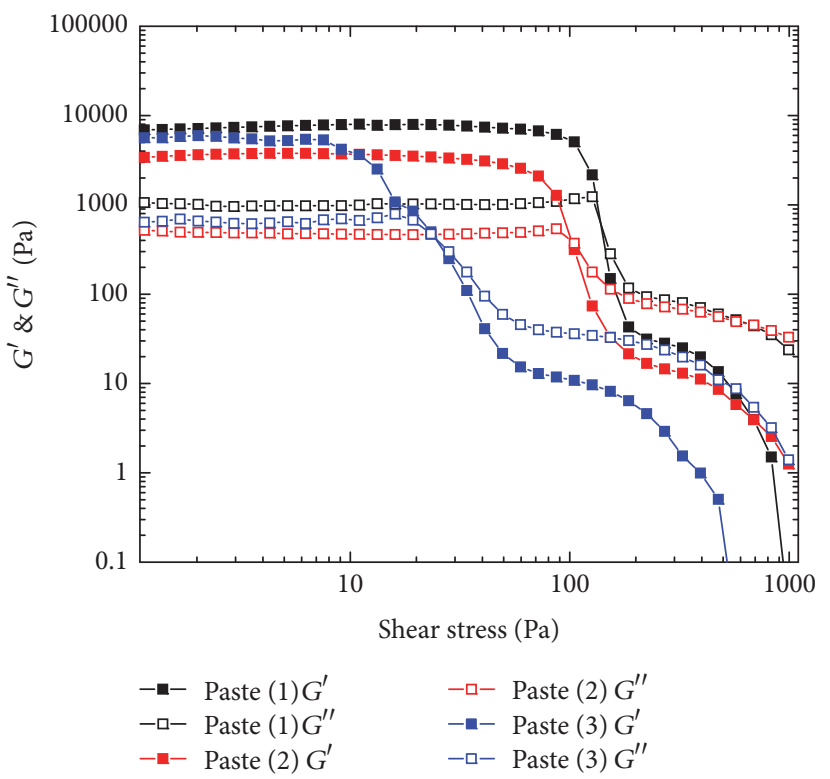

FIGURE 6: Storage moduli and loss moduli versus shear stress plot of Ag paste.

films printed on all surface exhibited much lower resistance at higher elongation compared to the patterned Ag electrode films. The order of low electrical resistance upon stretching was the same as the MW of binder polymer in the Ag pastes. This could be explained as follows although the electrical resistance versus elongation of Ag electrode film tests was performed after curing of the screen printed Ag pastes at $130^{\circ} \mathrm{C}$ for $30 \mathrm{~min}$. As the degree of unsaturation in the diacid monomer used to make binder polymer is the same, it can be assumed that the increase of $\mathrm{MW}$ of binder polymer after curing at $130^{\circ} \mathrm{C}$ for $30 \mathrm{~min}$ will show same trend in the order of MW as the uncured binder polymer. This suggests that the good dispersion and stability of the silver paste are very important in the mechanical properties of the resulting transparent conducting electrode films.

3.3. Bending Test of Silver Electrode Films. Bending tests were conducted with the relatively rigid polyester (PET) films on 


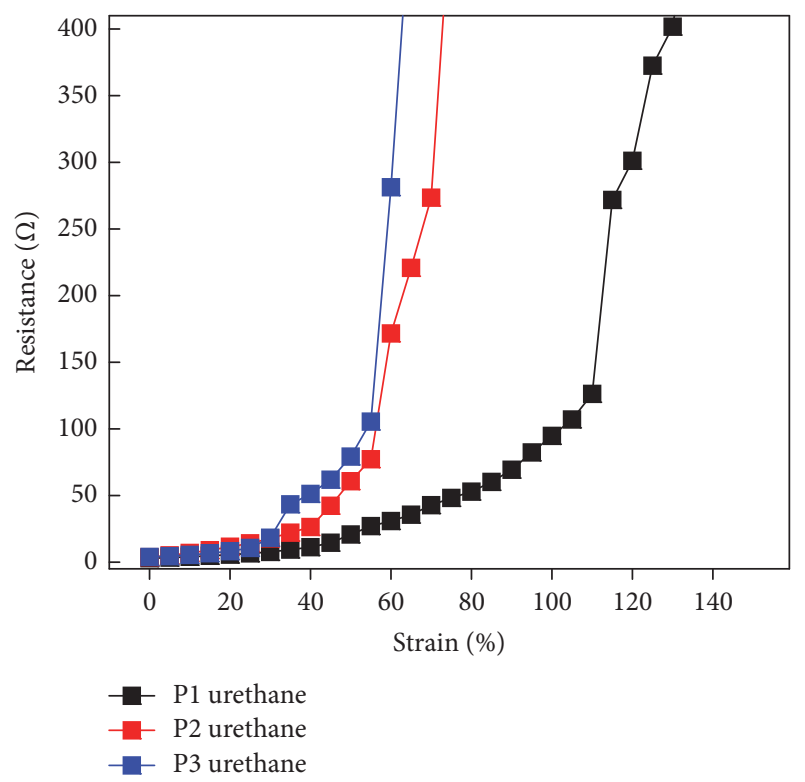

FIGURE 7: Electrical resistance versus tensile strain plot of patterned Ag electrode films.

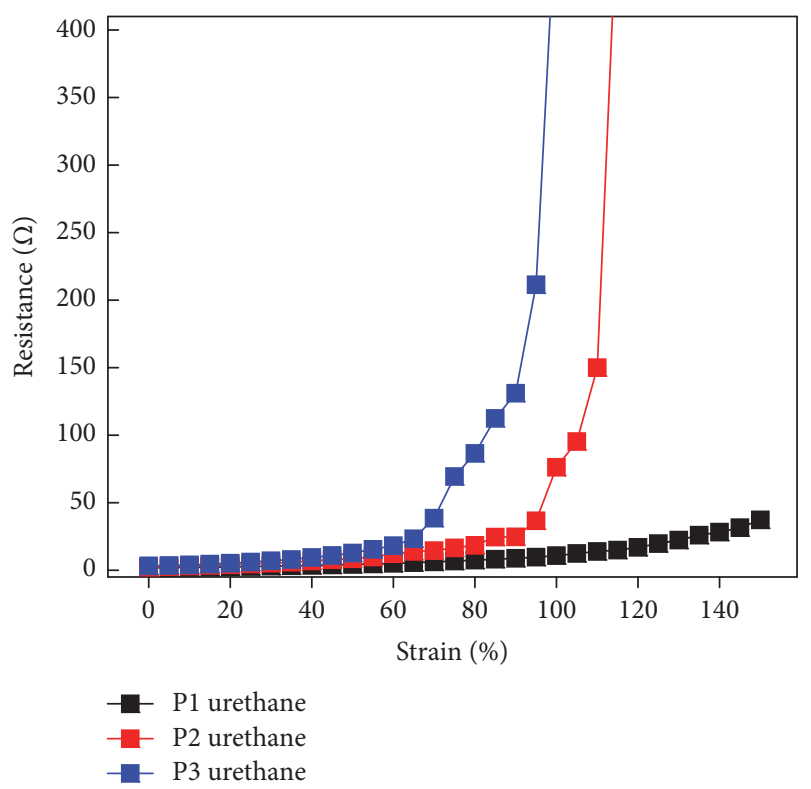

FIGURE 8: Electrical resistance versus tensile strain plot of unpatterned Ag electrode films.

which silver electrodes were patterned by screen printing. The bending radius versus electrical resistance plots were obtained in two different ways, that is, bending the $\mathrm{Ag}$ electrode films outside and inside as shown in Figures 9 and 10 , respectively.

The electrical resistance increased more in the outer bending than inner bending which indicated that the microcrack occurred in the outer bending. It was however noted that in the very small bending radius close to $1 \mathrm{~mm}$ the electrical resistance was increased in the outer bending while being

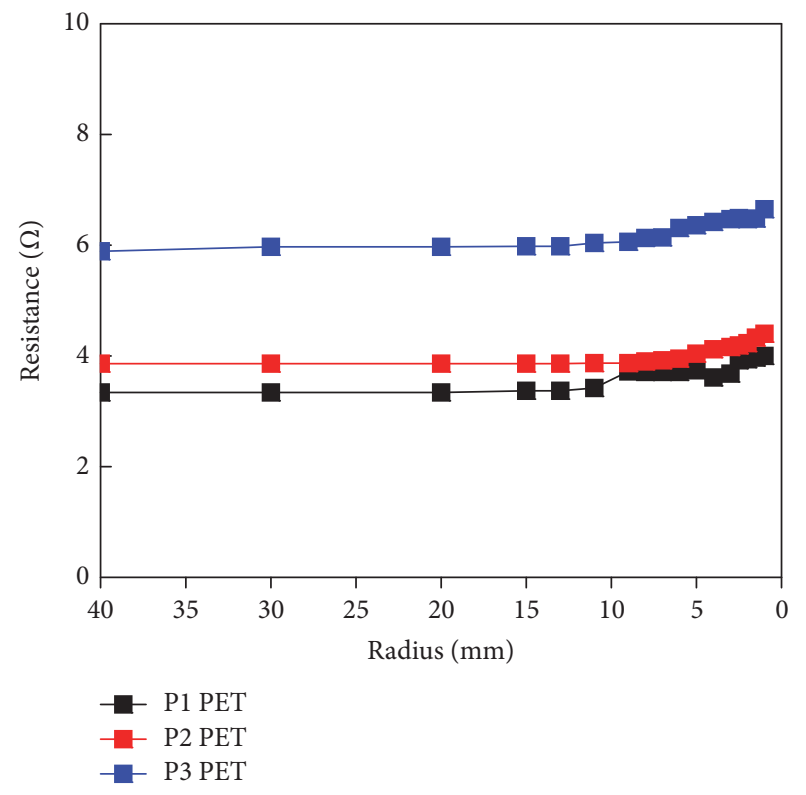

FIGURE 9: Electrical resistance versus radius of curvature plot for outer bending test.

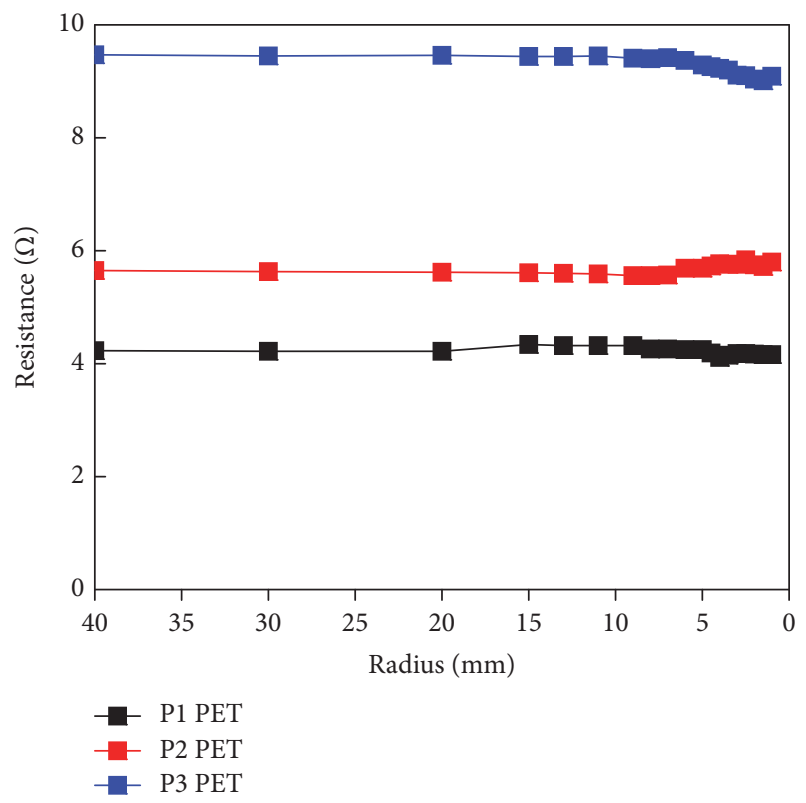

FIGURE 10: Electrical resistance versus radius of curvature plot for inner bending test.

decreased in the inner bending, suggesting that crack damage is larger in the outside bending in case of extreme bending.

The bending fatigue tests were also conducted both by outer and inner bending modes as shown in Figures 11 and 12 , respectively. As expected, the resistance was higher with increasing bending cycles in case of outer bending than inner bending, the same trend as the bending radius experiments. It is also noted that the bending fatigue tests conducted under $85^{\circ} \mathrm{C} / 85 \%$ relative humidity was found to be "pass" status. 


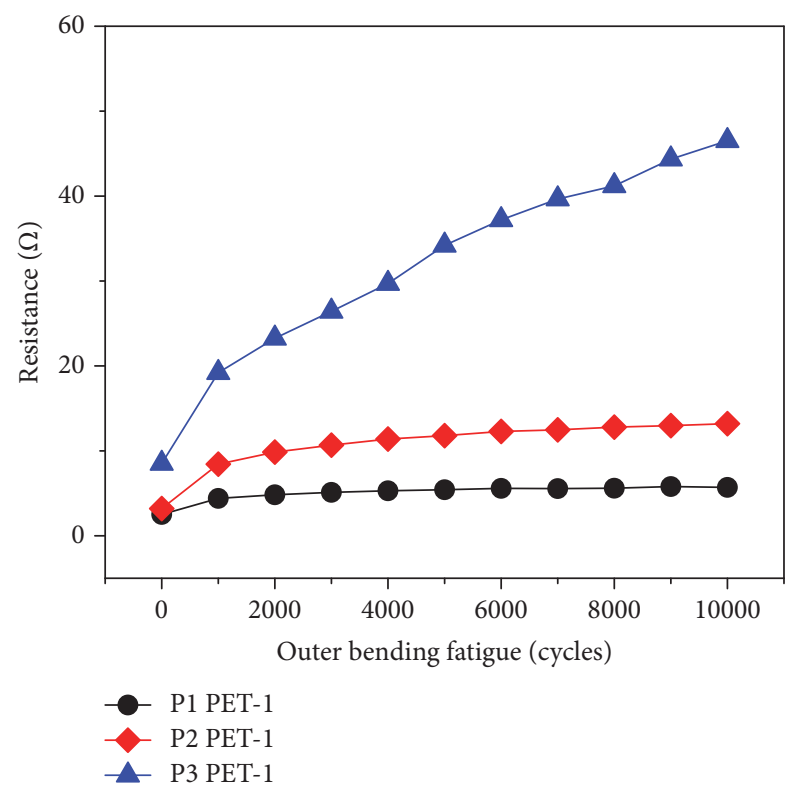

FIGURE 11: Electrical resistance versus bending cycle plot for outer bending fatigue test.

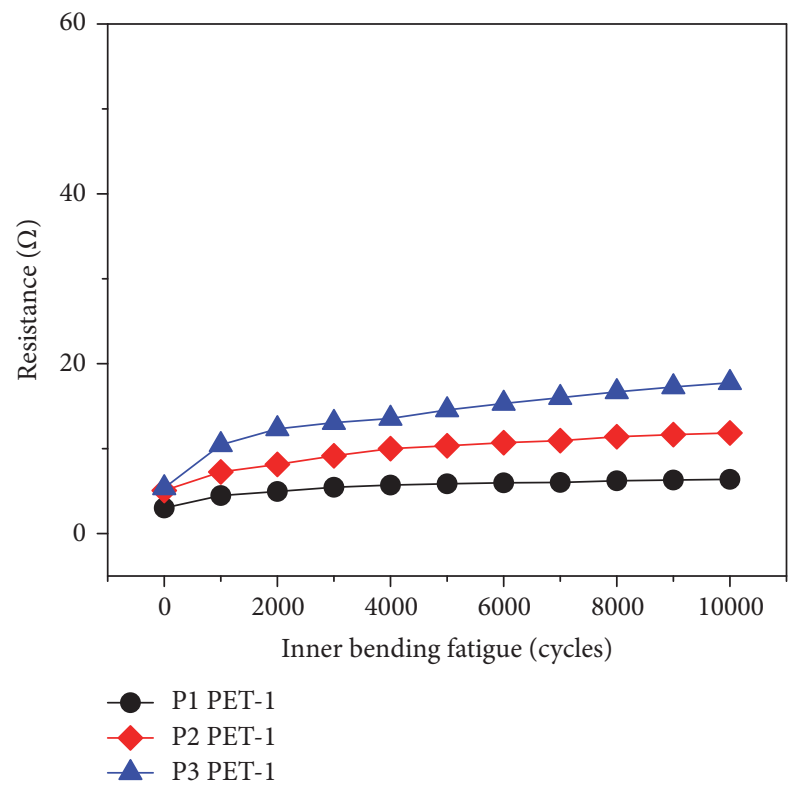

FIGURE 12: Electrical resistance versus bending cycle plot for inner bending fatigue test.

\section{Conclusions}

Silver paste was prepared by using unsaturated polyester resin as binder polymers with different molecular weights and glass transition temperatures. The transparent silver electrode patterns were obtained by screen printing on the flexible polyurethane and relatively rigid polyester films as substrates. The rheological study of Ag pastes showed that the binder polymer with high molecular weight and low glass transition temperature $\left(T_{g}\right)$ can stabilize Ag paste more effectively with the Ag particle content over $80 \%$ by weight. The stretching and bending tests of Ag electrode films obtained by screen printing indicated that good conductivity of Ag electrodes is also related to the stability of Ag paste obtained with the high molecular weight binder polymer.

\section{Conflicts of Interest}

The authors declare that there are no conflicts of interest regarding the publication of this paper.

\section{Acknowledgments}

This material is based upon work supported by the Ministry of Trade, Industry \& Energy (MOTIE, Korea) under Industrial Technology Innovation Program "Development of Stretchable Transparent Electrode Film with $3 \mu \mathrm{m}$ Line Space Based on Cu/Ag Composite Nanoparticles" (no. 10062220).

\section{References}

[1] T. Q. Trung and N.-E. Lee, "Flexible and stretchable physical sensor integrated platforms for wearable human-activity monitoringand personal healthcare," Advanced Materials, vol. 28, no. 22, pp. 4338-4372, 2016.

[2] Y.-M. Choi, K.-Y. Kim, E. Lee, J. Jo, and T.-M. Lee, "Fabrication of a single-layer metal-mesh touchscreen sensor using reverseoffset printing," Journal of Information Display, vol. 16, no. 1, pp. 37-41, 2015.

[3] K. Kim, B. G. Hyun, J. Jang, E. Cho, Y.-G. Park, and J.-U. Park, "Nanomaterial-based stretchable and transparent electrodes," Journal of Information Display, vol. 17, no. 4, pp. 131-141, 2016.

[4] W. Honda, S. Harada, T. Arie, S. Akita, and K. Takei, "Wearable, human-interactive, health-monitoring, wireless devices fabricated by macroscale printing techniques," Advanced Functional Materials, vol. 24, no. 22, pp. 3299-3304, 2014.

[5] N. Matsuhisa, M. Kaltenbrunner, T. Yokota et al., "Printable elastic conductors with a high conductivity for electronic textile applications," Nature Communications, vol. 6, 2015.

[6] S.-Y. Nam, C.-G. Lim, H.-M. Nam, and B.-S. Gyun, "The Properties of Printed Electrode Pattern on the Stretchable Films," Journal of Korean Society for Imaging Science and Technology, vol. 22, pp. 1-6, 2016.

[7] J. Suikkola, T. Björninen, M. Mosallaei et al., "Screen-printing fabrication and characterization of stretchable electronics," Scientific Reports, vol. 6, Article ID 25784, 2016.

[8] I. Lee, J. Lee, S. H. Ko, and T.-S. Kim, "Reinforcing Ag nanoparticle thin films with very long Ag nanowires," Nanotechnology, vol. 24, no. 41, Article ID 415704, 2013. 

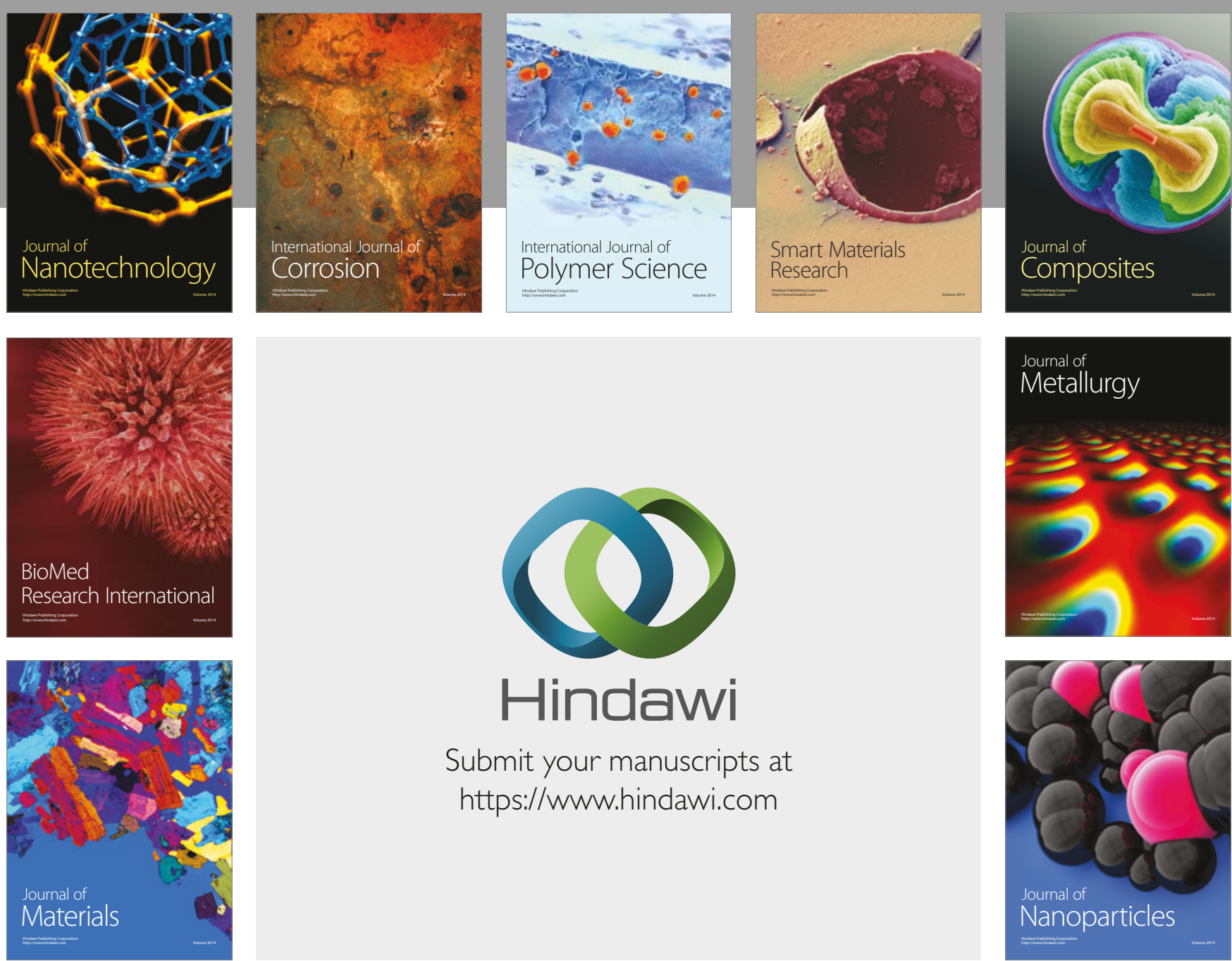

\section{Hindawi}

Submit your manuscripts at

https://www.hindawi.com
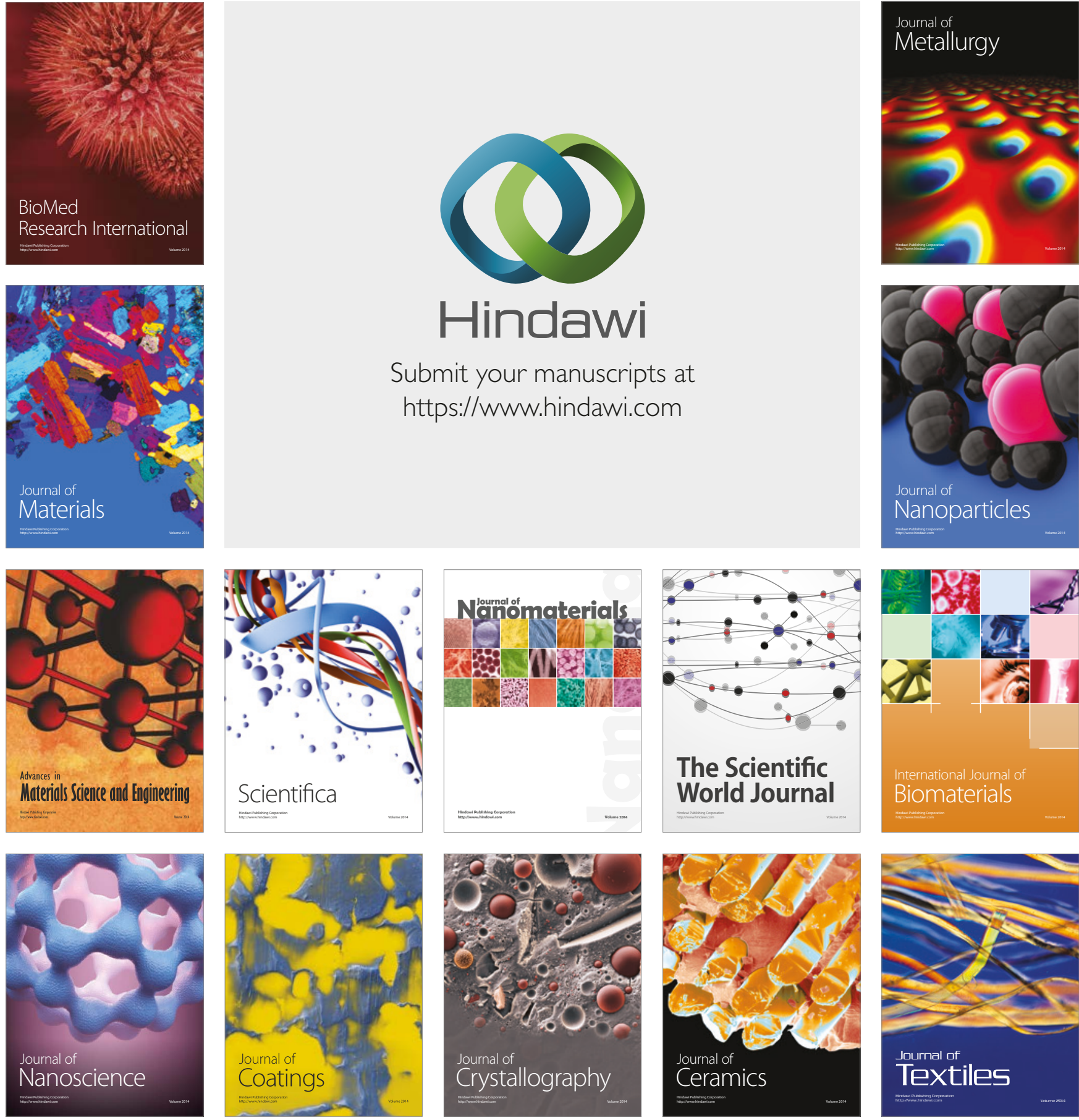

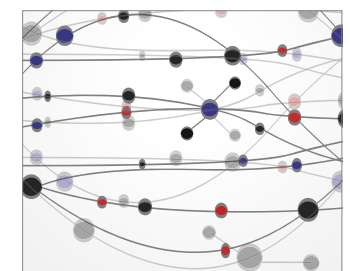

The Scientific World Journal
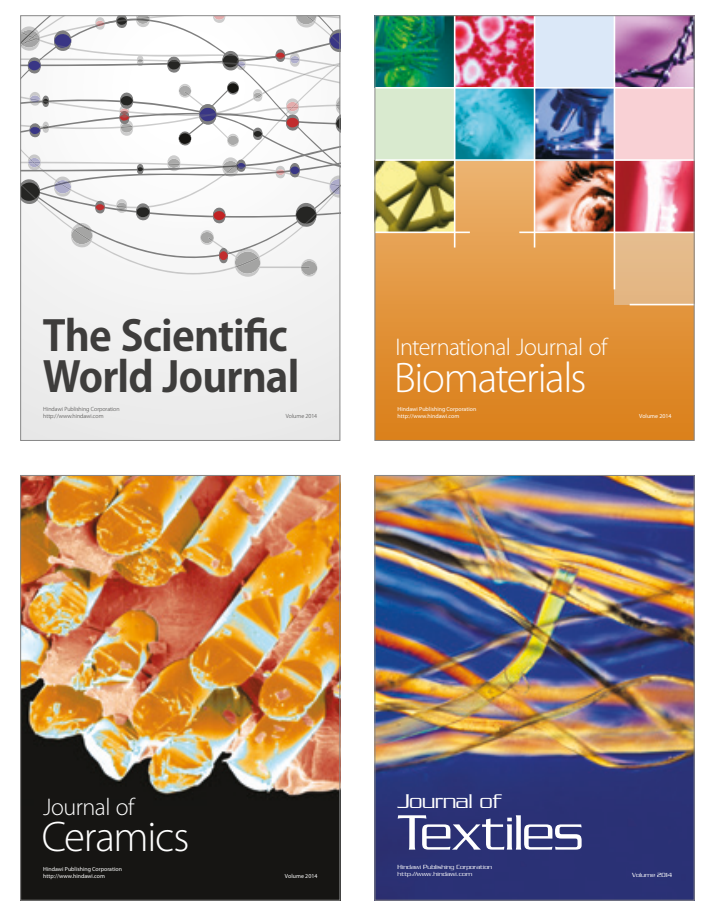